University of South Florida

DIGITAL COMMONS

Digital Commons @ University of

@ UNIVERSITY OF SOUTH FLORIDA

South Florida

QMaSC: A Handbook for Directors of

Quantitative and Mathematics Support Centers

USF Libraries

$1-1-2016$

\title{
22. Case Study: Symbolic and Quantitative Resource Center at Lewis \& Clark College
}

Margot Black

Lewis \& Clark College

Follow this and additional works at: https://digitalcommons.usf.edu/qmasc_handbook

\section{Recommended Citation}

Margot Black (2016), "Case Study: Symbolic and Quantitative Resource Center at Lewis \& Clark College", http://dx.doi.org/10.5038/9780977674435.ch22 in G. Coulombe, M. O'Neill, M. Schuckers (Eds.) A Handbook for Directors of Quantitative and Mathematical Support Centers, Neck Quill Press, http://scholarcommons.usf.edu/qmasc_handbook.

This Case Studies is brought to you for free and open access by the USF Libraries at Digital Commons @ University of South Florida. It has been accepted for inclusion in QMaSC: A Handbook for Directors of Quantitative and Mathematics Support Centers by an authorized administrator of Digital Commons @ University of South Florida. For more information, please contact digitalcommons@usf.edu. 


\title{
Case Study: Symbolic and Quantitative Resource Center at Lewis \& Clark College
}

\author{
(c) Margot Black, \\ Lewis \& Clark College
}

प्र

\section{Introduction}

The Symbolic and Quantitative Resource Center (SQRC) is an informal and free drop-in tutor center, staffed by undergraduate peer tutors, open to the entire Lewis \& Clark student body. Until the spring of 2013, the SQRC was known as the Math Skills Center (MSC). This case study will serve both as a study of the new center, but will also address the logistical and philosophical elements and challenges involved in its transition from MSC to SQRC.

Lewis \& Clark College is a private, selective, residential liberal arts college located in Portland, Oregon. In addition to offering Bachelor of Arts degrees in 28 majors in the College of Arts and Sciences, Lewis \& Clark is also home to a Law School with a top ranked Environmental Law program, and a Graduate School of Education \& Counseling. The College of Arts and Sciences is comprised of approximately 2000 students, most in the top quarter of their graduating class, representing all 50 states and 66 different countries. Popular majors are in the social sciences, but close to a quarter of all students major in the natural sciences, including mathematics and computer science. The college does not offer an education major (nor any pre-professional major), however the graduate school offers an M.A.T. degree in Education, with endorsements in Math, as well as Science, Art, Social Studies, and English. Undergraduate students choose to come to

Suggested Citation: Margot Black (2016), "Case Study: Symbolic and Quantitative Resource Center at Lewis \& Clark College", http://dx.doi.org/10.5038/9780977674435.ch22 in G. Coulombe, M. O'Neill, M. Schuckers (Eds.) A Handbook for Directors of Quantitative and Mathematical Support Centers, Neck Quill Press, http:// scholarcommons.usf .edu/qmasc_handbook.

This material is based upon work supported, in part, by the National Science Foundation under Grant DUE1255945. Any opinions, findings, and conclusions or recommendations expressed in this material are those of the author(s) and do not necessarily reflect the views of the National Science Foundation 
Lewis \& Clark for its small class sizes, extensive opportunities for overseas study, undergraduate research opportunities, beautiful campus, and dedicated faculty, well known for their commitment to excellent teaching.

The Math Skills Center was created in 1980 in response to a growing need for dedicated space and personnel to address and manage math remediation. Its creation coincided with the establishment of a remedial math course, Math 055 - Review of Intermediate Algebra, of which the Director of the MSC was the sole instructor of record. The center and the course were closely intertwined in a symbiotic and mostly static relationship for the better part of 30 years. Math 055 was taught in the MSC, either by the MSC director (for the lecture formatted sections) or facilitated by MSC tutors (for the self-paced sections). The MSC director was even in charge of placement testing to determine which students would take Math 055 and which were proficient enough to move onto college level math and science classes. At the time, "Mathematical Proficiency" at the intermediate algebra level was an official graduation requirement and the MSC was the place on campus designated to help students establish that proficiency and hence meet that requirement. Secondary to this, the MSC provided a space for students in lower division math classes to get help with their math homework.

Though the Math Skills Center was a valuable and well utilized resource, it was located in a hidden basement corner of campus and regarded as primarily a resource for weak students. Thus, many students were reluctant to visit the MSC even if they could find help there and faculty, wary of its stigma as a center for remedial math help, were reluctant to refer their students there. Students were more inclined to take advantage of the student-run and student-fee-funded one-on-one tutoring program (all Lewis \& Clark students can have up to 2 hours per week per course of one-on-one peer tutoring). Despite its mission statement to help students with "any math problems they encounter, including those which arise in classes outside the Mathematics Department," only students in lower level math classes patronized the MSC. Likewise, Math 055, the course that justified the Math Skill Center's very existence, was not popular among students, as it did not offer any credit towards graduation. Nor was the course popular with faculty and administrators who felt that a selective college had no business offering a remedial math course.

The retirement of the MSC's longtime director in the spring of 2011 created an opportunity to completely rethink the need for and function of Math 055 and the MSC. A math department faculty member stepped in as interim director - an experiment in how much leadership the center required - and a new course was developed to replace Math 055: CS102 - Quantitative Reasoning, a course designed to improve quantitative reasoning skills rather than to remediate algebra. These events coincided with the college receiving a generous grant from the Teagle Foundation. The grant proposal, written in response to a growing realization that students were graduating from the college without having improved their quantitative reasoning abilities, had two main objectives: 1) Develop a pilot course (CS102) to address the issue, and 2) expand the role and function of the Math Skills Center to support such a course and to support strengthening QR skills in general. 
The remedial math content of Math 055 was absorbed into the new course's curriculum, however, unlike Math 055, CS102 was structured more traditionally in that it would not be self-paced with MSC tutor support, nor taught in the MSC, nor taught by the [interim] MSC director. Without Math 055 to teach and support, and other tutoring options available on campus, it wasn't clear that the Math Skills Center would be utilized at levels justifying its expense. Under the interim director, and with reduced staffing, the usage and efficacy of the MSC were under close observation in $2011 / 12$ by an administration looking to tighten its belt.

Fortunately, it was observed that the MSC was still just as necessary as ever, if even just to support CS102 through peer tutoring, so a new director was appointed for the 2012/13 year. At that time, the faculty piloting CS102 handed off the entirety of the teaching, assessment, and curriculum development duties to the new director, and thus a new relationship between the MSC and quantitative reasoning was born.

By virtue of this shift in curricular priorities, and with a great deal of financial help from the Teagle Foundation's grant, the MSC has undergone a major transformation. Moved to a new, more central space, and given a new name, the Symbolic and Quantitative Resource Center also has a new and expanded mission: to support and enhance symbolic and quantitative reasoning across the curriculum and campus community.

The SQRC is still in its early phases of this transition and is still navigating its evolving role in supporting the pursuit and development of quantitative reasoning skills at the college, both in and out of the mathematics department. Many new services that will appeal more broadly to the campus community are on the horizon. At present, the SQRC primarily accomplishes its new mission by simply expanding its drop-in tutoring services to students in all quantitative courses at all levels, not just lower level math classes. To this effect, the center has tutors qualified to assist students not just in mathematics but also in statistics, computer science, physics, chemistry, economics, logic, quantitative reasoning, and quantitative research methods courses. But more than just a homework help center, visitors to the SQRC can find additional resources for their courses such as course textbooks, computers with software such as R, Excel, SPSS, STATA, LaTeX, and Mathematica, as well as enthusiastic tutors who are trained to help students engage with the material in a way that will foster greater independence with it.

As previously alluded to, the center has just completed its relocation from an obscure basement location to a more central, accessible, and visible location in the main entry of the building where all math and social science courses are taught. This relocation has had a profound effect on the SQRC. Though exact figures aren't available, we know that more than double the number of students visit the SQRC in its new location. The new location also well positions the SQRC to become a greater part of the campus community, greatly expand its curricular reach and scope of services, and rebrand itself as a center that provides both academic support and enrichment.

The new SQRC occupies 655 square feet of an almost exactly square space (see Figure 1), right 
inside the main door of the newest and largest classroom building on campus. The space was formally used as a café (long since defunct) followed by an underutilized student lounge space. Through some summer remodeling and necessary funding by the college, the SQRC could open its doors in the fall of 2013. A wall-to-wall, floor-to-ceiling sliding glass door - the only barrier between the center and the noisy passing time traffic — was converted into a wall-to-wall, floor-toceiling white board, a favorite attribute of the new space. The sliding glass door was fixed in place at the edge of a new doorway that was installed, forming the interior entrance to the SQRC. The door is secured by a keypad lock to which only tutors have the code (they are able to program it to stay unlocked for student passage). The SQRC also has an exterior entrance, unlocked from the inside by sliders, or from the outside with a Math Department key (not available to tutors). Tutors open the center from the interior entrance, unlock the exterior doors, and then students using the center can (and do) access the room from both entrances. It is nice to have a location with exterior windows so that students can easily tell when it is open if it is dark outside and so that both tutors and students feel safer there at night.

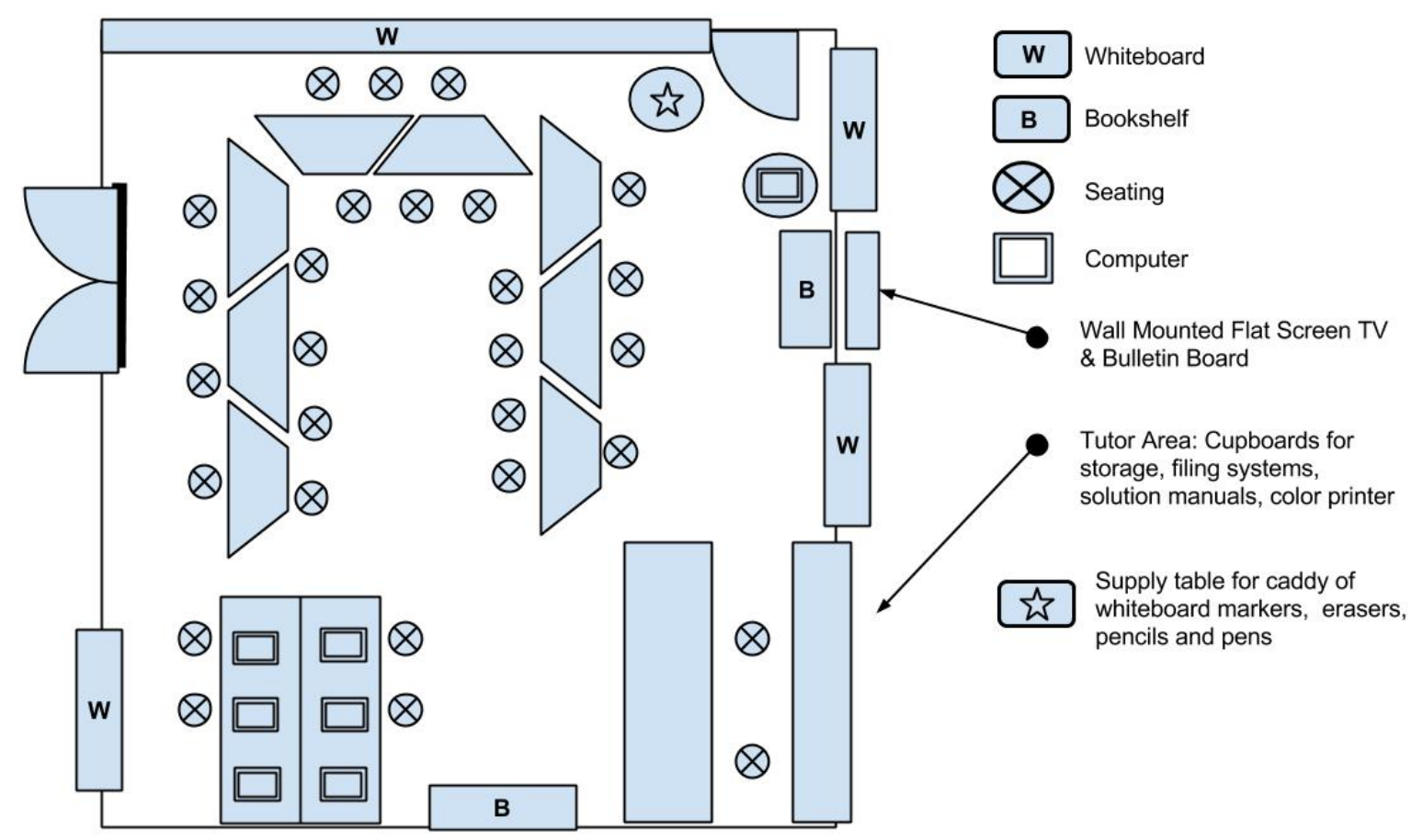

Figure 1: SQRC Floor Plan

Just inside the interior door is a computer sign-in station; all students visiting the center are required to sign in using a Google form (see Appendix). After signing in, the students can take a seat at one of 8 trapezoidal tables (which can be rearranged into many different formations), 
or at one of the six computers in the SQRC: 4 iMacs and 2 PCs. The computers are kept on tall tables that can be walked up to, but four stools are provided. Rarely are all 6 computers in use at one time. The SQRC has two bookshelves for student use. A small bookshelf holds supplemental course resources (such as old textbooks and laminated 'Quick Study' guides) as well as office supplies for student use such as whiteboard markers, scratch paper, graph paper, a stapler, 3-hole punch, pencils and pens, rulers, electric pencil sharpener, tape, etc. A larger bookshelf is the new 'textbook library'. It holds all current textbooks for SQRC supported courses, another very popular feature of the new space. Students can use the books only while they are in the center and many students do use them to work on their homework in between classes.

The room still has the back counter and front counter of the defunct café; these have been repurposed as tutor and file storage. The front counter provides a nice space for students to walk up to for quick questions. The back counter has a color printer that can be used by students to print out materials and assignments for quantitative courses. It also holds a countertop filing system that is used for students to turn in their homework, or for professors to leave supplemental materials, or student work to be handed back. (Files are made as needed for any professor that requests them.) Solution manuals are locked in one of the cupboards and are generally only utilized by tutors. Graphing calculators are also kept locked up and can be checked out by students with their student ID. We do allow students to leave the center with a calculator as they are often checked out for use on an exam. Thanks to the vestiges of the café, the back counter also has a sink, mini-fridge, and a coffee maker. The latter two are employee perks that the tutors greatly appreciate. Tutors can sit in one of two stools (soft seating with a chair back) that are generally positioned in between the two counters.

On Sundays and during the evening, when the center is busiest, two nearby classrooms are reserved for SQRC overflow. Tutors are instructed to move study groups, or other groups of students studying similar material (i.e., Chemistry and Physics) to the overflow rooms before the center becomes overwhelmed.

\section{Center Organization and Services}

Organizationally, the SQRC is an autonomous entity, independent of any other department. Its personnel is comprised of student tutors and the director. The director, officially reports directly to the Dean of the College, but generally consults with the Math Department chair for most matters. Historically, the Math Skills Center employed between 16 and 20 tutors a semester, but the SQRC has required an increase in personnel due to an increase in traffic and its expansion of services. It currently employs about 30 tutors, five of which exclusively tutor chemistry, and three of which are hired by the physics department to primarily tutor physics. The remaining can all tutor math as well as other subjects such as computer science and economics. The SQRC currently operates 
with an annual budget of $\$ 12,600$, of which $\$ 11,000$ is for payroll, and the remainder for supplies and other operational miscellany. However, given the greatly increased demand of the SQRC, and the end of the Teagle grant's financial support of the SQRC, a budget of $\$ 25,000$ was approved for the following school year. At present, chemistry and dedicated physics tutors are paid out of their department's budgets.

Despite its departmental autonomy, the SQRC is unofficially a part of the close-knit Math Department family. The director, who is required to hold at least a Master's degree in Mathematics, and who has always been hired by a Math Department search committee, keeps an office in the math department, attends department meetings, and relies heavily on the department's administrative assistant.

This relationship with the math department actually led to some difficulty in determining a new name for the center. With the relocation of the center and planned expansion of services, and also in an effort to shed the reputation of being just a support center for those struggling in basic mathematics, it was generally agreed upon that a new name was in order. Determining the new name was left up to the director and the math department, though it ultimately needed approval from the Dean. A first and popular suggestion was 'Quantitative Resource Center'. However, math faculty felt that since the center would still primarily focus on math, they didn't want its new name to suggest otherwise. Also, though mathematics and quantitative reasoning are certainly related, one is not a subset of the other. Pure mathematics is more symbolic in nature than quantitative; hence, 'Symbolic' was appended to the name 'Quantitative Resource Center'.

The director, a full-time exempt staff member on a 9-month contract, has three primary responsibilities: running the center, teaching CS102, and administrating the Quantitative Reasoning Exam (QRE).

- The first entails submitting and managing the yearly budget, staffing the center — including interviewing, hiring, supervising, and training the tutors - advertising, marketing and assessing the center's services, communicating with the math department and campus community regarding matters pertinent to the center and tutors, and making sure that the center is in good working order with regard to supplies and educational resources.

- As for teaching, the college currently offers two or three sections a semester of CS102 and the Director of the SQRC is its sole instructor, responsible for the instruction, assessment, and curriculum development of the course as well as advising students in the class.

- Finally, with the help from the Math Department's administrative assistant, the director is in charge of administering the 'Quantitative Reasoning Proficiency Exam.' The test places students into CS102, or determines that they are proficient enough in intermediate algebra to move onto their college level math and science courses. Responsibilities of administering the test include maintaining information about the test on the college's website, providing review 
materials, assessing the testing instrument (currently using the commercial product ALEKS PPL), advertising and proctoring the exam at various times during the year, and advising students based on their results.

The SQRC is typically open everyday except Saturday, with hours during both daytime: midmorning until 5 PM, and evening: 6 PM until 10 PM. The actual schedule varies from semester to semester and day to day depending on the number of tutors, their availability, and demand. The schedule is posted on the doors of the SQRC, announced in classes, and placed as a Google Calendar on the SQRC's website.

Usually one to two math tutors staff the center at all times with an additional chemistry or physics tutor available in the late afternoons and evenings. Many of the math majors are qualified to tutor in other subjects such as physics, computer science, and economics and those specialties are advertised accordingly. For special courses, such as logic and quantitative research methods, specific tutors and tutor hours are advertised to students in course syllabi.

When students arrive at the center they are prompted by the tutor on duty to sign in at the signin computer (right inside the interior entrance). After signing in, they can take a seat and ask for help immediately, work independently or in a study group, or make use of the new textbook library. Students may also come in to turn in homework, or to use or get help with Excel, Mathematica, R, STATA, SPSS, LaTeX, or other software.

When tutors are assisting students they are encouraged only to write on the whiteboards, rather than on a student's paper. More importantly, the SQRC has about a dozen mini whiteboards, 2' $\mathrm{x} 3$ ' pieces of white board material purchased and cut to size at Home Depot, which students are encouraged to use while in the SQRC rather than a pencil and paper. These whiteboards better facilitate group work and collaboration, and encourage productive brainstorming. The whiteboards are very popular among both students and tutors. Indeed, even professors often borrow several for group work in their classes.

\section{Staffing, Hiring and Training}

The SQRC tutoring staff is comprised exclusively of student peer tutors. Historically, tutors were recruited through their math professors, who were asked to identify strong students with a good demeanor and helpful attitude. This year, in an effort to expand the areas of expertise of tutors, professors were also asked to recruit students with strong computing skills, experience with statistics, and double majors. Currently the chemistry and physics departments recruit and hire their own tutors but the SQRC director schedules and supervises them. Similarly, students that tutor for more specialized non-math and science courses, such as logic and research methods, are recruited directly by the courses' professors. 
Many of the referred tutors are math majors, but since the center has historically only served lower division courses, the only requirement is successful completion of Calculus 2. A requirement that tutors have successfully completed Discrete Mathematics and Calculus 3 (multivariable calculus) is currently being considered as many students now come into the center for help with these classes.

The following is the process of hiring math tutors: each spring professors are invited to recommend strong students with helpful demeanors as potential new SQRC tutors. The director then emails the referred students an application and invitation to arrange an interview. Hiring is ultimately based on goodness-of-fit, how many positions there are to fill, and whether or not a student has work-study. The position does not require work-study but those with work-study are given preference in hiring. In addition, rising sophomores are given higher priority than juniors or seniors as the SQRC is looking to find students who will be on staff for $2-3$ years of their college career. A tutor's position has always been automatically renewed if they express interest in continuing the position; they are not required to re-interview and they generally stay on from semester to semester, year to year, returning to the SQRC even after they have studied overseas for a semester. Tutors start at minimum wage (currently $\$ 9.10 /$ hour in Oregon) and get a $\$ 0.25 /$ hour raise per semester of service.

This hiring process has consistently resulted in hiring great tutors for the center; however, there always seem to be well-qualified and enthusiastic students that fall through the cracks of the professor referral system. Thus, this year the SQRC will have an open application process but still ultimately require candidates to be recommended by their professors. Only those students who are strongly recommended by their professors will be invited to an interview.

As previously discussed, one to three tutors staff the center at any given time. The earliest shifts usually have only one tutor, as they tend to have the fewest number of students visiting; by $1 \mathrm{PM}$ there are two tutors on staff, and after dinner (6 PM - $10 \mathrm{PM})$ there are two to three math tutors as well as a physics or chemistry tutor. The evening is the busiest time for the center. A tutor will typically work two $1.5-2.5$ hour shifts each week.

The MSC's budget is not currently adequate for extensive training. Tutors attend one paid 2-hour mandatory meeting each semester that includes both orientation (in the fall) and some tutor training. A representative from Student Support Services attends and discusses learning styles, learning differences, and multicultural sensitivity. To mitigate this lack of training, less experienced tutors usually only work with more experienced tutors, rarely by themselves on a solo shift.

The Writing Center at Lewis \& Clark uses a 1-credit hour Practicum course as a means of training its tutors. Such a course is being piloted in the spring semester of 2014 at Lewis \& Clark for the SQRC. If successful, it will be offered yearly in the fall and will be required of all new tutors. The course will meet for one hour, weekly, with the intent of training tutors in best practices with 
regards to effective tutoring, training tutors to use various types of software used in quantitative courses, and as an opportunity to talk about what is coming up in various courses so that tutors can be ready for challenging material.

\section{Community Interactions}

Interaction between the old Math Skills Center and the campus community was minimal outside of the Math Department, and somewhat scant even then. Indeed, its location made it difficult to find for all but the very determined! Although there was general acceptance that the MSC's existence was essential, its reputation as a remedial math hub and support center for underprepared students meant that non-math faculty and the administration kept their distance. However, due largely to the new and improved central location of the SQRC, as well as its new focus on quantitative reasoning rather than remedial mathematics, community interaction and appeal have increased considerably.

The SQRC is mainly a place where students go to meet with peer tutors, but given that the center is located in the same building where all of the math and social science classes are taught, professors often pop in on their way to or from class to drop off papers or supplemental materials and also to assist their students. Additionally, all math professors can use their key to access the center, and other professors can obtain the door code if they request it. This has enabled some professors to hold review sessions in the center when it is not otherwise open, which they are welcome and encouraged to do. Having professors hold office hours in the center has been considered but is not, at this time, on the horizon.

The entire faculty has generally expressed their support and enthusiasm for the SQRC and their desire to interact with it, thus further plans to increase its exposure are underway. Plans include faculty development, especially in supporting individual and departmental attempts to infuse nonquantitative courses with elements requiring quantitative reasoning. This may take the shape of faculty trainings, as well as individual mentorship and course support in the SQRC.

Many potential opportunities and ideas for the growth and trajectory of the SQRC, especially as it pertains to community exposure, will be subject to the soon-to-be formed SQRC Advisory Committee. Until now, neither the MSC, nor SQRC, have had an advisory committee. The proposed committee will comprise of $6-8$ members of faculty across the curriculum and will focus on, among other things, ways that the SQRC can interact with and impact the entire campus community. One exciting possibility that will be discussed is how the SQRC can help create and support a scientific component of the Writing Center! 


\section{Assessment at the Center}

The only formal assessment of the center to date occurs during the external evaluation of the math department. Internal efforts to rigorously assess the center are in their nascent stages. One item for assessment is who is using the center, and why. In the past the tutors would tally the number of students in specific classes in the center during their shift, with a large group of classes left for the 'other' category. The new sign-in system also collects this information, and more (See Appendix). This will enable the director to monitor unique versus return visits (student IDs are required) and also allow us to compare the grades of the students who visited the SQRC with those who did not, as a way of possibly assessing its efficacy. A student feedback form, on paper and on the computer, will also be instituted this year. Absent of this feedback, assessment has largely been anecdotal, or via tutor survey, but even these methods have motivated positive change. Indeed, the relocation of the center was the direct result of loud and frequent complaints that the old center was hard to find and felt 'dungeon-like' (a further punishment for those who struggled with mathematics).

At the end of a tutor's shift, he or she fills out a shift report (See Appendix). The shift report is also a Google Form, the responses of which populate a spreadsheet that is reviewed by the director daily. These shift reports are a valuable source of information for the director and a good way of keeping track of how the center is running on a day-to-day basis. Part of the shift report is called 'Top Topics' where tutors can enumerate specific questions or concepts that multiple students asked about. In the future this information will be sent to professors so that they know for what topics their students are using the center.

\section{Acknowledgements}

We would like to thank the National Science Foundation for its generous support of the QMaSC Workshop through NSF grant number 1255945. Any opinions, findings, and conclusions or recommendations expressed in this material are those of the author(s) and do not necessarily reflect the views of the National Science Foundation.

I would like to thank the Teagle Foundation for its generous collaborative Engaging Evidence grant to Lewis \& Clark and Willamette College. Through this grant the director of the SQRC has been able to connect with other center directors and become fully engaged and immersed in the national community of center directors and quantitative reasoning. If not for this grant, the writer would not be writing right now. 


\section{Appendices}

\section{MSC Student Sign-in Form}

* Required

Please enter your student $I D$ *

This information will not be shared, nor connected with your name. It helps us to track the center usage.

This is a required question

What brings you in today? *

(Select all that apply)

I need help with homework

I am studying for a quiz / test

I need help with Excel / R / SPSS / STATA / LaTeX / Mathematica

I'm just working on my homework; I'll get help if I need it

Meeting a study group

Picking up a review / skill sheet

I generally need help understanding concepts from class

What subject are you here for today? *

(If you are here for more than one please fill out the survey twice.)

MATH (Including CS102)
Computer Science
Economics
Chemistry
Physics
POLS 201 (Quantitative Research Methods)
Other

s created inside of Lewis \&amp; Clark College.

buse - Terms of Service - Additional Terms

Figure 2: 


\section{End of Shift Report}

* Required

Name: *

How many hours did you work today? *

Round (up*) to the nearest quarter hour. (*Unless you're just a few minutes over.)

Hrs $\$:$ Mins $\$:$ Secs $\$$

Tell me about your shift... *

Was it busy? What students were in the center? Any issues? Any supplies needed?

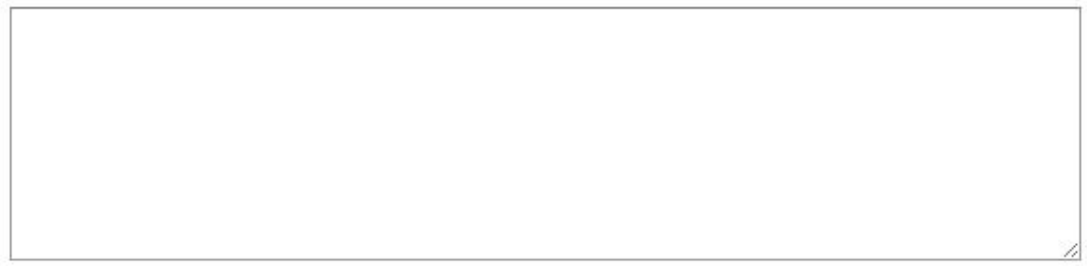

TOP TOPICS: Please tell me about questions / homework problems / concepts that several students asked for help with. *

This information is very helpful to professors. It would also be great if you wrote these up on the board for the next group of students and tutors :)

Figure 3: 